\title{
Um estudo pós-colonial, com o uso da semiótica, sobre capas de livros clássicos editados no Brasil e nos Estados Unidos
}

\author{
MARIANA LUZ EIRAS QUEIROZ ${ }^{1}$ \\ MARCUS WILCOX HEMAIS ${ }^{1}$ \\ Luís AlexandRe PeSsôa ${ }^{1}$
}

\author{
${ }^{1}$ Pontifícia Universidade Católica do Rio de Janeiro (PuC-RIo) / Departamento de AdMinistração, Rio de JANEIRO - RJ, BRASIL
}

\begin{abstract}
Resumo
O controle exercido pelos países do Norte global sobre as nações que foram colonizadas se reflete nos contextos culturais e ideológicos dessas sociedades. Um desses reflexos é encontrado em capas de livros clássicos, que são o objeto desta pesquisa, a qual pretende analisar como são representados o Norte e o Sul globais no projeto gráfico de capas de livros clássicos brasileiros e estadunidenses. Para alcançar esse objetivo, foi realizada uma análise semiótica dos planos do conteúdo e da expressão em 304 capas de livros, com base na teoria formulada por Jean-Marie Floch. No conjunto de obras estudadas, buscou-se verificar elementos geopolíticos no projeto gráfico de capas, em que nível os elementos estadunidenses são reforçados nas capas editadas no Brasil e como os itens brasileiros aparecem nas capas editadas nos Estados Unidos. Para tanto, utilizou-se a teoria de Edward Said sobre orientalismo como base para essa verificação, observando-se que os títulos brasileiros, quando editados nos Estados Unidos, são carregados de estereótipos criados pelo Ocidente, enquanto os livros estadunidenses, quando editados no Brasil, refletem as mesmas representações encontradas nas capas daquele país.
\end{abstract}

Palavras-chave: Pós-colonialismo. Orientalismo. Capa de livro. Elementos geopolíticos. Semiótica.

\section{A post-colonial study, using semiotics, on classic book covers edited in Brazil and the United States}

\begin{abstract}
The control exercised by the countries of the Global North over the colonized nations is reflected in the cultural and ideological contexts of these societies. One of these reflections is found in classic book covers, which are the object of this research that analyzes how the Global North and Global South are represented in the graphic design of Brazilian and American classic book covers edited in Brazil and the United States. A semiotic analysis of the content and the expression plans was performed on 304 book covers, based on the theory formulated by Jean-Marie Floch. Within the set of works analyzed, we sought to verify the existence of geopolitical elements in the graphic design of book covers, at what level American symbols are reinforced on the covers edited in Brazil, and how the Brazilian symbols appear on the covers edited in the United States. Edward Said's theory of Orientalism was used as the basis for this verification, and it was observed that Brazilian titles, when published in the United States, are loaded with stereotypes created by the West, while American books, when published in Brazil, reflect the same representations found on the covers of that country.
\end{abstract}

Keywords: Postcolonialism. Orientalism. Book cover. Geopolitical elements. Semiotics.

\section{Un estudio poscolonial, utilizando la semiótica, sobre portadas de libros clásicos editados en Brasil y Estados Unidos}

\section{Resumen}

El control ejercido por los países del norte global sobre las naciones colonizadas se refleja en los contextos culturales e ideológicos de esas sociedades. Uno de esos reflejos se encuentra en las portadas de libros clásicos, que son el objeto de esta investigación que pretende analizar cómo el norte global y el sur global están representados en el diseño gráfico de portadas de libros clásicos brasileños y estadounidenses. Para lograr este objetivo, se realizó un análisis semiótico de los planos de contenido y de expresión en 304 portadas de libros, basado en la teoría formulada por Jean-Marie Floch. Dentro del conjunto de obras analizadas, se intentó verificar la existencia de elementos geopolíticos en el diseño gráfico de portadas de libros y hasta qué punto se refuerzan los símbolos estadounidenses en las portadas editadas en Brasil y cómo aparecen los símbolos brasileños en las portadas editadas en Estados Unidos. Para ello, se utilizó la teoría del orientalismo de Edward Said como base para esta verificación y se observó que los títulos brasileños, cuando se publican en Estados Unidos, están cargados de estereotipos creados por Occidente, mientras que los libros estadounidenses, cuando se publican en Brasil, reflejan las mismas representaciones que se encuentran en las portadas de ese país.

Palabras clave: Poscolonialismo. Orientalismo. Tapa de libro. Elementos geopolíticos. Semiótica. 


\section{INTRODUÇÃO}

O colonialismo sofrido por sociedades do Sul global ainda persiste atualmente (Young, 2003) por meio do controle que o Norte exerce sobre o resto do mundo com relação ao que é considerado desenvolvido ou subdesenvolvido e aos caminhos para alcançar o desenvolvimento (McEwan, 2018). Esse controle se materializa em vários contextos culturais e ideológicos, pois os colonizadores sempre trataram povos colonizados como inferiores, que precisam de salvação e incentivos para atingir um estado de civilização. Tal visão se tornou, então, uma justificativa ideológica para o mundo eurocêntrico exercer seu imperialismo sobre o resto do mundo (Mignolo, 2011).

Um dos autores pós-coloniais que mais se destacaram ao debater a maneira como o Norte se relaciona de maneira imperialista com o Sul é Edward Said. Sua principal teorização é a que versa sobre orientalismo (Said, 2007), pela qual estabelece as bases pelas quais o mundo eurocêntrico define o Oriente. Nesse processo, eurocêntricos criam uma imagem que distorce o que são orientais, ao mesmo tempo que exaltam sua superioridade. Segundo o autor, uma das formas como isso ocorre se dá quando o mundo eurocêntrico tenta agrupar povos "outros" sob terminologias que, aos olhos dos colonizadores, podem parecer senso comum, como América, Ocidente, Oriente ou Islã. Todavia, ao fazê-lo, reduzem a diversidade de tais povos e inventam identidades coletivas que, na verdade, somente servem para reforçar estereótipos cuja principal função é fazer o diferente parecer mais familiar.

Nesse processo colonizador, deslocam-se as complexidades culturais inerentes a todo e qualquer povo, reduzindo, então, suas histórias e identidades. Esses traços culturais, com o tempo, vão sendo perdidos. Consequentemente, conforme Said explica, o oriental só existe para o mundo pela óptica do ocidental, cuja visão sempre compara "o outro" a si, rebaixando-o, dada sua suposta falta de desenvolvimento. Dessa forma, o oriental é uma representação, uma imagem, que pouco retrata o que, de fato, esse indivíduo é (Said, 2007).

Tal processo colonial, discutido por Said, tem se expandido globalmente, e uma forma como isso vem sendo facilitado é por meio da disseminação de livros e de literatura do Norte. Enquanto o mundo eurocêntrico desenvolve sua literatura com requintes que afirmam sua importância intelectual e cultural para o restante do mundo, o Sul busca em sua expressão literária uma afirmação nacionalista e patriótica, de valorização da cultura, da história e do conhecimento local (Bosi, 2004).

Além das narrativas, outro elemento relacionado a livros que também apresenta contornos coloniais é o projeto gráfico de capas. Por meio desse conjunto de estímulos, sobretudo de suas capas, livros têm sido usados para ilustrar diferenças entre as representações do Norte e do Sul (Heller, 2011). Todavia, o estudo de capas, em especial por autores de diferentes áreas de conhecimento, é incomum (Camargo, 2016; Hanes, 2014; Machado, 2017; Melo, 2014), sendo ainda mais escassas as pesquisas que associam tais elementos visuais à discussão pós-colonial.

Em marketing, essa realidade não é diferente. Alguns estudos da área se dedicam a analisar livros, editoras e o comportamento de consumidores desses produtos (Noorda, 2019; Ozuem, Howell \& Lancaster, 2019), porém pouco falam sobre particularidades gráficas de livros, como as capas, e a forma como são utilizadas para finalidades coloniais. Tanto a capa quanto o miolo são importantes para o estudo desse tipo de produto. Em particular no Brasil, quando o número de leitores aumentou, a partir da década de 1950, graças ao aumento da população universitária, as editoras precisaram aperfeiçoar as estratégias para atrair esses novos consumidores. A adoção de práticas de marketing passa, então, a fazer parte do design do livro, pois as capas começam a ser tratadas "como instrumento de sedução no ponto de venda" (Melo, 2014). Portanto, embora haja uma conexão clara entre marketing e capas, a relação geopolítica desses elementos é deixada em segundo plano.

Tal postura não deve ser estranhada, haja vista que discussões de natureza pós-colonial têm sido, em geral, ignoradas, de forma que pouco se reconhece como as relações entre o Norte e o Sul são mantidas hierarquicamente desiguais, fomentando, assim, as assimetrias de poder entre ambas as partes (Jack, 2008; Varman, 2018). Todavia, mais recentemente, diferentes autores têm rompido com essa tradição, mostrando como o marketing vem sendo utilizado como elemento colonizador pelo Norte (Nurcahya, Hafiar \& Nugraha, 2018; Touzani, Hirschman \& Smaoui, 2016; Varman \& Costa, 2013). Em proximidade com o pensamento de Said (2007), tais autores mostram de que modo diferentes realidades associadas ao Sul são controladas pelo Norte (Touzani et al., 2016) e, assim, (re)construídas, a fim de representar tais realidades como locais cultural e epistemologicamente atrasados, subalternizados e dependentes (Varman, 2018; Varman \& Costa, 2013). 
É acompanhando essa linha de estudos críticos que o presente trabalho busca analisar de que maneira são representados o Norte e o Sul globais no projeto gráfico de capas de livros clássicos brasileiros e estadunidenses. Para alcançar esse objetivo, foi realizada uma análise semiótica de 304 capas com as características descritas, utilizando-se como base a teorização de orientalismo desenvolvida por Said (2007).

Além desta Introdução, o presente artigo traz outras 5 seções. A próxima discute a teorização de Said sobre orientalismo. A terceira explora a metodologia utilizada no trabalho para coletar os dados e analisar o corpus da pesquisa. A quarta analisa os resultados encontrados no estudo. A quinta apresenta uma discussão sobre a análise dos dados. Por fim, na sexta, são elencadas as considerações finais do trabalho.

\section{O ORIENTALISMO DE EDWARD SAID}

Orientalismo é uma das teorias entre os estudos pós-coloniais que discutem o poder que alguns povos exercem sobre outros a partir do momento que os primeiros detêm controle sobre o que é conhecimento e a forma como esse conhecimento é utilizado (Ashcroft, Griffiths \& Tiffin, 2007). É com base nesse conceito de poder que Edward Said desenvolve sua interpretação sobre orientalismo, a fim de mostrar de que forma o Norte controla o Sul, mesmo após o fim das colonizações (Ashcroft et al., 2007).

É importante ressaltar que, quando se refere aqui a Norte e Sul, não se está adotando uma postura meramente geográfica para caracterizar tais conceitos. Conforme Boaventura de Sousa Santos, tais classificações são, na verdade, epistemológicas, podendo haver diversos "suis globais" no Norte, assim como há "nortes globais" no Sul. Todavia, "dado o desenvolvimento desigual do capitalismo e a persistência do colonialismo ocidentalocêntrico, o Sul epistemológico e o Sul geográfico sobrepõem-se parcialmente, especialmente no que se refere aos países que foram sujeitos ao colonialismo histórico" (Santos, 2019). Quando Said desenvolve sua teorização, portanto, usa o mesmo tipo de princípio. Ainda que França, Grã-Bretanha e Estados Unidos sejam referências utilizadas pelo autor para representar o Ocidente e sua relação com o Oriente - referenciado por Ásia e Oriente Médio -, tal escolha se dá puramente por questões práticas. Seu foco, na verdade, é apresentar as "generalizações históricas" (Said, 2007) que a episteme Ocidental criou ao elaborar o conceito de orientalismo.

É com esse entendimento que Said (2007) desenvolve sua teorização, baseada na distinção ontológica e epistemológica entre Oriente e Ocidente. Para ele, o Oriente foi moldado pela cultura ocidental como um espaço no qual exotismo, encantamento e magia fazem parte de suas realidades, em contraste com o conhecimento e a razão que dominam a episteme ocidental. Foi criada, então, uma hegemonia cultural eurocêntrica, que reforçou a crença, entre povos de tal origem, de que terem uma identidade cultural superior a outros não eurocêntricos (Memmi, 1992).

O Oriente, dessa forma, acabou sendo retratado como um espaço atrasado e em necessidade de salvação. Em razão disso, o saber, o conhecer, os significados, os padrões e as formas de expressão de tais povos não eurocêntricos foram subalternizados pelos colonizadores (Spivak, 2010), que impuseram as próprias crenças, expressões e imagens aos colonizados, como forma de controle social e cultural (Bhabha, 1994), transformando a cultura eurocêntrica num modelo universal a ser adotado por todos (Castro-Goméz, 2002).

O mundo eurocêntrico, portanto, ao gerar tais comparações entre espaços epistêmicos, passou a definir o que é o oriental e, mais ainda, o que é o ocidental. O Oriente, dessa forma, só existe para o mundo pela forma como o Ocidente o representa, num processo de constante comparação do "outro" com si, por meio do qual "eles" são tidos como inferiores a "nós", pois não alcançaram "nosso" grau de desenvolvimento (Said, 2007). O oriental nada mais é do que uma representação/imagem, que distorce o que, de fato, esse indivíduo é, alterando sua essência (Bhabha, 1994). Por sua vez, o ocidental é aquele que representa o ápice da civilização moderna, pois, diferentemente de seu par oriental, evoluiu e é, agora, o centro do mundo (Said, 2007).

Said (2007) explica que é desse distanciamento "artificial" entre um espaço epistêmico e outro que surge o conceito do "outro", criado com o objetivo de tornar clara a suposta separação ontológica e epistemológica entre o colonizador e o colonizado. Assim, o sujeito dominador adquire uma sensação de que detém poder, por isso acredita que o sujeito dominado é seu dependente. Nesse processo, o colonizado passa a ser objetificado, enquanto o colonizador é um indivíduo - com o eu (self) que se constitui "em si mesmo e para si mesmo por meio de seus discursos e sua capacidade de reflexão" (Quijano, 2007). Já o objeto é considerado uma entidade externa a esse sujeito, ou seja, o outro, que tem uma natureza diferente da dele. 
A teorização de Said sobre orientalismo ofereceu a pesquisadores do Sul uma perspectiva crítica que Ihes permitiu romper as tradições eurocêntricas e colocar em xeque o controle que o Norte ainda exerce sobre o resto do mundo. Diferentes áreas de conhecimento vêm se valendo de tais argumentações, inclusive a de marketing (Jack, 2008; Varman, 2018). Em seus questionamentos, pesquisadores de linha crítica mostram como o Norte impôs ao Sul sua forma de pensar - apesar de essa forma eurocêntrica de pensamento ser pouco útil para explicar tais realidades -, apagando, assim, o conhecimento local que fora criado em linha com os interesses desse contexto (Varman \& Sreekumar, 2015). Ao fazê-lo, o Norte acaba por criar um sentido de dependência de instituições do Sul por conhecimento estrangeiro, por acreditarem que esse é o melhor e mais adequado para resolver seus problemas (Rodrigues \& Hemais, 2020). Sob essas perspectivas críticas de pensadores da área, é possível vislumbrar que a teorização de Said (2007) seja adequada para analisar fenômenos pós-coloniais em marketing, entre eles o escolhido para o presente estudo.

\section{METODOLOGIA}

As capas dos livros que são objeto desta pesquisa foram analisadas com base na semiótica discursiva de linha francesa. Embora esse viés teórico-metodológico seja mais comum em marketing em estudos interpretativistas (Lima \& Pessôa, 2018) e sobre comunicação e branding (Lawes, 2020) do que nos de cunho crítico, há evidências de que a semiótica possa ser utilizada adequadamente como metodologia de análise em pesquisas pós-coloniais (Carlson, 2008; Mignolo, 2009), inclusive dentro da área (Hemais, Pessôa \& Barros, 2019), corroborando a escolha aqui feita.

Ao longo da presente pesquisa, foram observados o plano do conteúdo e o plano da expressão, com base na teoria formulada por Jean-Marie Floch. Juntos, os dois planos dão origem aos sistemas semissimbólicos, "que se definem pela conformidade não entre os elementos isolados dos dois planos, mas entre as categorias da expressão e categorias do conteúdo" (Floch, 2001, grifo nosso).

Os sentidos do texto - que, para a semiótica, pode ser verbal, visual ou sincrético - são analisados primeiramente pelos mecanismos e pelos procedimentos do plano do conteúdo. A metodologia dessa análise é concebida sob a forma de um percurso gerativo dos sentidos (Greimas \& Courtés, 2008). Na análise das capas dos livros, foi usada a terceira etapa desse percurso: o nível discursivo, considerada a mais complexa e concreta. Para isso, foram observados, no plano do conteúdo, os elementos que aparecem na superfície do texto, ou seja, os temas e as figuras que figuram nas capas.

As histórias contadas nos livros que compõem o corpus de pesquisa representam a tematização, na qual os traços semânticos do discurso aparecem de forma abstrata. Já na figurativização, esses traços aparecem como efeitos sensoriais, seja por meio de cores e formas, seja por meio da iconização, que produz efeitos de realidade a partir do momento em que se reconhecem figuras do mundo real (Barros, 2003).

Após a análise do plano do conteúdo, foi feita a do plano da expressão. Segundo Teixeira (2008), são as categorias do plano da expressão que dão forma ao sentido. Para esta análise, foram usadas as categorias cromáticas, eidéticas e topológicas. Enquanto a primeira diz respeito às combinações das cores, a segunda leva em conta as relações entre as formas, ao passo que a terceira está relacionada à posição e à orientação das formas no espaço.

De modo a manter a perspectiva pós-colonial adotada no presente estudo, as análises semióticas foram realizadas em conjunto com outras baseadas na teorização sobre orientalismo. Said (2007) explica que o Oriente é uma representação cultural desenvolvida pelo mundo eurocêntrico, que pouco se aproxima da realidade desse "outro" espaço epistemológico. Todavia, essa é a representação disseminada mundo afora e que pauta a relação assimétrica entre o Norte e o Sul. Dessa forma, ao analisar as capas de livros clássicos estadunidenses e brasileiros, busca-se entender se as imagens presentes ilustram essa assimetria de representações, o que justifica a escolha pela teorização de Said (2007) para a realização de tal exame no presente estudo.

Embora a investigação desenvolvida aqui se concentre em analisar as capas de livros clássicos de dois países, um associado ao Norte e o outro, ao Sul, deve-se entender a escolha por Estados Unidos e Brasil mais como representação de tais epistemologias do colonizador e do colonizado do que como locais geográficos propriamente ditos, até porque, conforme Santos (2019) explica e anteriormente apontado aqui, "suis globais" podem ser encontradas no Norte, assim como "nortes globais" podem estar presentes no Sul. A escolha por basear a análise das capas de livros dos Estados Unidos para representar o Norte se 
deu para seguir a mesma lógica adotada por Said. Para o autor, "desde a II Guerra Mundial, a América tem dominado o Oriente" (2007), o que mostra a proeminência geopolítica global desse país e, por isso, justifica sua adoção para a análise sobre o conceito de orientalismo. No presente caso, a partir da Segunda Guerra Mundial, quando o bloqueio naval inglês impediu que livros provenientes da Europa fossem importados para o Brasil, os livros do Novo Mundo, tanto de autores hispano-americanos quanto, e principalmente, de autores dos Estados Unidos, passaram a representar $43 \%$ das importações de livros (Hallewell, 2005). Logo, escolher livros clássicos dos Estados Unidos faz sentido para o atual estudo, haja vista a importância que a cultura literária estadunidense historicamente apresenta para a realidade brasileira.

A escolha por analisar as capas de livros clássicos brasileiros é justificada pelas preocupações demonstradas por pesquisadores locais sobre como o marketing pensado e praticado localmente tem sido controlado pela epistemologia dominante do Norte (Boschi, Barros \& Sauerbronn, 2016; Veludo-de-Oliveira, Quintão \& Urdan, 2014). Considerando que livros são produtos e, por isso, estão associados a marketing (Noorda, 2019; Ozuem, Howell \& Lancaster, 2019), as inquietações desses pesquisadores podem perfeitamente englobar os projetos gráficos de tais produtos, pois estes também estão sujeitos a retratar a geopolítica aqui discutida. Tais aflições, todavia, não devem ser entendidas como únicas ao Brasil, porquanto em outros países não eurocêntricos os mesmos tipos de questionamentos acerca das representações gráficas em capas de livros também são encontrados (Ünsür, 2020). Desse modo, mais do que uma questão geográfica, o problema do marketing e das capas de livros do Sul pode ser considerado epistêmico e pertinente a todos os espaços que formam tal episteme. Logo, dentro desse contexto, a adoção de um país - no caso, o Brasil - para analisar as capas de livros clássicos se faz adequada, já que suas representações se aproximariam das de outros países do Sul.

As capas de livros brasileiros foram pré-selecionadas após consulta à publicação História concisa da literatura brasileira, de Alfredo Bosi (2004). Foram separados os títulos mais importantes dos movimentos literários romantismo, realismo, pré-modernismo e modernismo.

Após essa etapa, foi feita uma pesquisa na Estante Virtual, ${ }^{1}$ que vende livros usados - os clássicos aparecem numa classificação melhor de venda na lista de mais vendidos do referido site. Essa verificação serviu para averiguar, entre os livros mais importantes dos gêneros literários citados acima, quais eram os mais vendidos no Brasil. Em seguida, foi feita uma pesquisa em diversos sites nacionais e internacionais para verificar quais seriam os títulos com uma diversidade maior de capas e que, assim, serviriam melhor ao propósito diacrônico deste estudo, ao tentar encontrar uma similaridade de propostas dentro dos objetos analisados. Ao fim, foram selecionados 4 clássicos brasileiros: Iracema (1865), de José de Alencar; Memórias póstumas de Brás Cubas (1881), de Machado de Assis; Os sertões (1902), de Euclides da Cunha; e Gabriela, cravo e canela (1958), de Jorge Amado.

A escolha dos títulos estadunidenses foi feita após consulta à publicação Perfil da literatura americana, de Kathryn VanSpanckeren (2006), editada pelo Departamento de Estado dos Estados Unidos, pela qual se pode tomar conhecimento dos livros que são considerados os clássicos daquele país. Em seguida, os títulos com maior diversidade de capas editadas, tanto no Brasil quanto nos Estados Unidos, foram os escolhidos, chegando a um número de 4 obras: $O$ último dos moicanos (1826), de James Fenimore Cooper; Moby Dick (1851), de Herman Melville; A cabana do pai Tomás (1852), de Harriet Beecher Stowe; e $O$ grande Gatsby (1925), de F. Scott Fitzgerald.

Como sugere o método adotado por Pessôa (2013), "a fase de coleta de material da pesquisa observou critérios de relevância e de representatividade, de modo a autorizar a identificação das estratégias [...] discursivas mais significativas" para o corpus analisado.

Após a coleta das capas, procurou-se observar todas elas em conjunto, como num mood board, ${ }^{2}$ a fim de identificar as figuras que apareciam com mais frequência, como feito por Pessôa, Barros e Costa (2017). Esse processo permitiu estabelecer 4 categorias que mostram como os símbolos que cercam a construção de capas de livros são usados. São elas: autor representado - apresentam ilustração, caricatura ou foto do autor do livro -, personagens representados - contêm personagens da história -, paisagem - apresentam fotografias, ilustrações ou pinturas que fazem referência ao universo narrado nas histórias - e ícones ${ }^{3}$ representados - não trazem figuras humanas como principal tipo de manifestação. As imagens que compõem essas capas representam ideias ou passagens que são contadas nas histórias.

\footnotetext{
${ }^{1}$ Recuperado de www.estantevirtual.com.br/livros-mais-vendidos/literatura-brasileira

Mural, com imagens, que serve para organizar visualmente uma ideia.

${ }^{3}$ Segundo Melo e Ramos (2011), "desenhos, ou ícones, são sínteses visuais que guardam uma certa autonomia em relação ao texto; eles não o substituem nem o redundam, e sim o traduzem em nova chave, uma chave genuinamente visual".
} 
Foram encontradas, em menor número, composições do tipo all type - composições visuais feitas somente com texto verbal, sem imagens -, que não são contempladas na análise, pois o objetivo maior é identificar o significado dos símbolos visuais presentes nas capas. Nem todos os títulos apresentam capas em todas as categorias. O objeto de interesse deste estudo se concentra nas capas de clássicos editadas a partir de 1950, período durante o qual a cultura estadunidense começa a difundir-se mais intensamente na sociedade brasileira (Hallewell, 2005).

Ao todo, selecionaram-se 440 capas. Não foram consideradas na análise as de edições adaptadas para o público infantojuvenil; nem aquelas que, após identificação criteriosa das editoras, se descobriu serem inglesas, e não estadunidenses; nem as de uma mesma editora com poucas modificações gráficas e que, portanto, não justificavam a análise de composições similares; nem as que não atendiam ao critério de terem sido publicadas a partir da década de 1950. Após as exclusões, do total de 440 , foram analisadas 304 capas.

\section{ANÁLISE SEMIÓTICA DAS CAPAS DE LIVROS CLÁSSICOS ESTADUNIDENSES E BRASILEIROS}

O primeiro ponto que se nota é a quantidade superior de capas de livros estadunidenses editadas no Brasil. O mesmo não ocorre com as obras brasileiras editadas nos Estados Unidos. Além de aparecerem em menor número, as capas de títulos brasileiros não recebem a mesma atenção dedicada à composição do layout que as estrangeiras recebem aqui.

O número elevado de capas da categoria "personagens representados" ocorre tanto nos títulos estadunidenses quanto nos brasileiros, editados nos respectivos países. Percebe-se uma fidelidade, por parte das editoras brasileiras, às características das personagens desenvolvidas lá fora. No entanto, quando se trata dos títulos brasileiros, as personagens somem das capas editadas nos Estados Unidos.

A editora brasileira L\&PM, nas capas analisadas de $O$ grande Gatsby, por exemplo, usa a mesma imagem ${ }^{4}$ editada no exterior, só alterando o texto verbal para o português (Figura 1). Nenhuma editora estadunidense do conjunto analisado faz o mesmo nas capas de títulos brasileiros.

Figura 1

\section{Comparação entre a capa da Editora L\&PM e a capa da Oxford University Press}

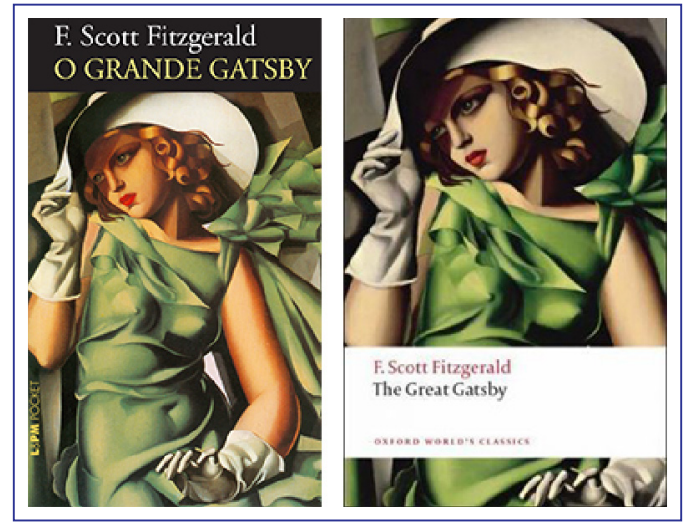

Fonte: Editora L\&PM (2004) e Editora Oxford University Press (1998).

Uma exceção está nas capas do romance de Jorge Amado. Todas as capas estadunidenses de Gabriela, cravo e canela analisadas trazem a personagem principal representada, porém essa representação não é fiel às características de Gabriela. Na capa de 2006 da editora Alfred Knopf, por exemplo, Gabriela é representada como uma menina jovem e de olhar malicioso (Figura 2). Não lembra a Gabriela de Jorge Amado, uma sertaneja retirante que foi para cidade em busca de uma vida melhor. 
Figura 2

Editora Alfred Knopf (2006)

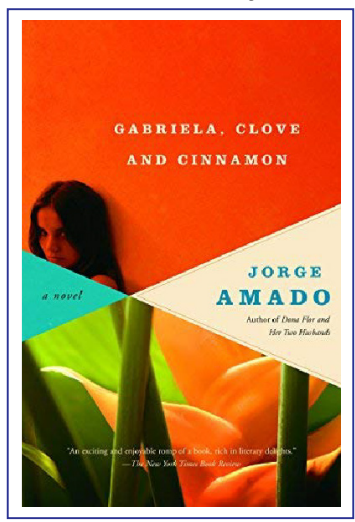

Fonte: Editora Knopf (2006)

A capa da Avon Books, de 1967, mais uma vez, mostra uma Gabriela nua, mais sensual e envolta em flores do tipo copo de leite (Figura 3), que não é originária do Brasil nem se adapta bem a regiões tropicais.

Nas capas das editoras estadunidenses, percebe-se também uma falta de entendimento da cultura brasileira ao identificar que parte delas apresenta referências a culturas de outros países e a estilos gráficos que não fazem ou não fizeram parte dos estilos adotados por artistas nacionais, como a similaridade de traços na ilustração de Memórias póstumas de Brás Cubas com a obra de Paul Klee e a utilização, por outra editora, de uma caveira de estilo mexicano na capa do mesmo romance.

No conjunto analisado, nenhuma capa de livro estadunidense lançado por editoras brasileiras traz referência à bandeira dos Estados Unidos ou apresenta o predomínio das cores azul e vermelho. Já nas capas de livros brasileiros editados naquele país, percebem-se as cores verde e amarela e também a bandeira do Brasil, como nas de Iracema, além de imagens com plantas, folhagens e florestas, o que ocorreu em todos os títulos brasileiros editados nos Estados Unidos analisados, o que pode reforçar o estereótipo de que o Brasil é um lugar selvagem (Scheyerl \& Siqueira, 2008) (Figura 3).

Figura 3

Plantas, folhagens e florestas em capas de títulos brasileiros lançados por editoras estadunidenses
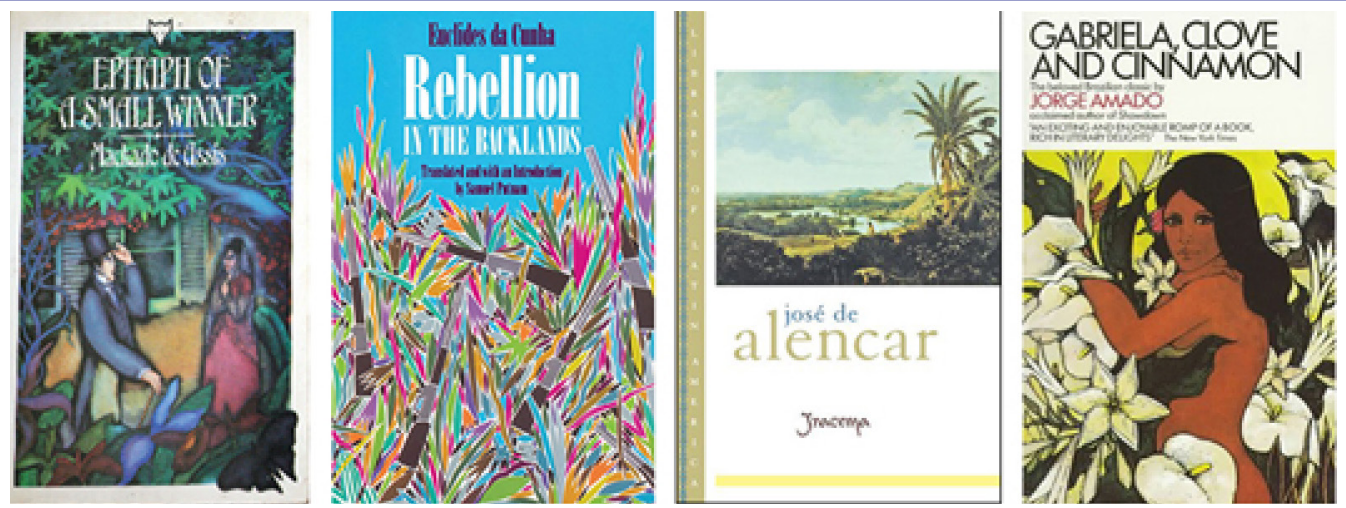

Fonte: Editora Trafalgar Square (1985), Editora University of Chicago Press (2010, 2000) e Editora Avon Books (1967).

Nas capas estadunidenses de livros brasileiros, é comum o uso de termos que indicam que a obra é literatura brasileira ou latino-americana ou que o autor é brasileiro (Figura 4). Já nos livros estadunidenses editados no Brasil, não há ocorrência desse tipo de indicação. As obras são consideradas clássicos mundiais e, portanto, não precisam de especificação de origem. As classificações que aparecem são: "obras célebres", "clássicos universais", "clássicos da literatura universal", "clássico da literatura em grande tradução" e, no caso específico da capa da Editora BestBolso de O grande Gatsby, de 2007, "O grande clássico da moderna literatura norte-americana" (Figura 5). 
Figura 4

\section{Classics of Brazilian literature e Brazil's greatest classic}
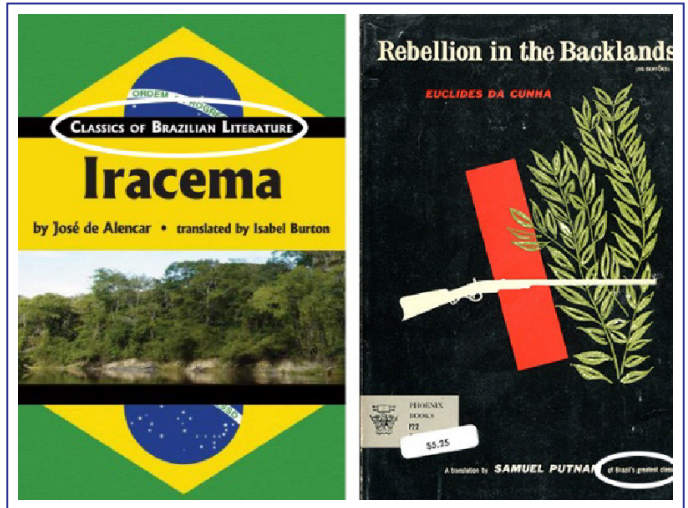

Fonte: Editora Luso-Brazilian Books (2008) e Editora University of Chicago Press (1957).

Figura 5

Clássicos universais e o grande clássico da literatura norte-americana

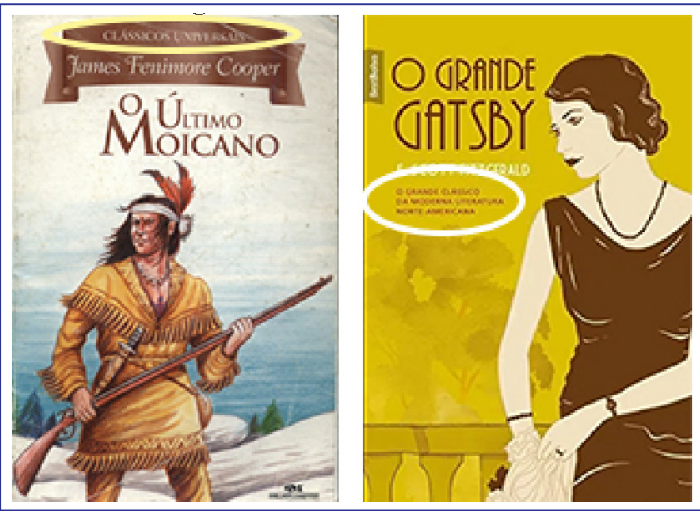

Fonte: Editora Melhoramentos (2008) e Editora BestBolso (2007).

No Brasil, todos os títulos estadunidenses analisados tiveram edições especiais lançadas, com projeto gráfico elaborado, capa dura e ilustrações exclusivas (Figura 6). 0 inverso parece não ocorrer, já que não foi encontrada nenhuma capa de edição especial dos títulos nacionais analisados.

Figura 6

Edições especiais de títulos estadunidenses editados no Brasil

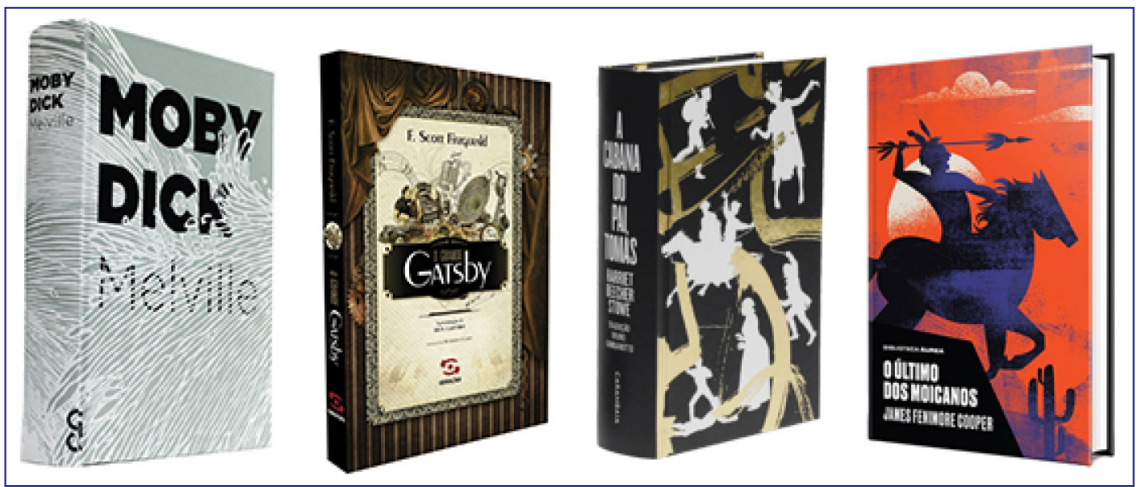

Fonte: Editora Cosac Naify (2008), Editora Geração Editorial (2013), Editora Carambaia (2018) e Editora Nova Fronteira (2018). 
O romance que teve mais edições nos Estados Unidos foi Memórias póstumas de Brás Cubas. Em 2020, 2 editoras estadunidenses publicaram a obra de Machado de Assis, e, ao contrário das de outros títulos brasileiros analisados, as capas recentes das editoras Penguin e Liveright demonstram cuidado nas escolhas gráficas na hora da diagramação (Figura 7).

Figura 7

Edição da Penguin (2020) e da Editoria Liveright (2020)

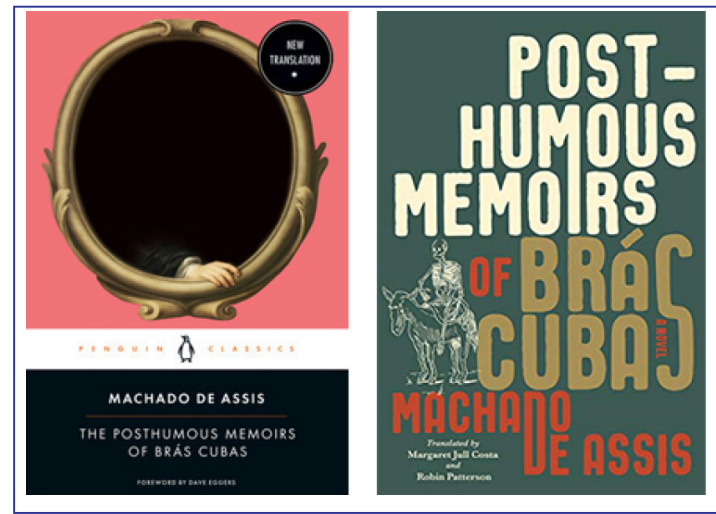

Fonte: Editora Penguin Random House (2020) e Editora Liveright (2020).

Algumas editoras estadunidenses, contudo, editam as capas com o nome completo de Machado: Joaquim Maria Machado de Assis, enquanto outras utilizam somente Machado de Assis. Essa falta de identidade no livro do brasileiro também ocorre com a tradução do título. Em algumas capas, o título é The posthumous memoirs of Brás Cubas, enquanto em outras é Epitaph of a small winner. Observa-se o mesmo tipo de ocorrência nas capas de Iracema. Ora o autor aparece como José de Alencar, ora como José Martiniano de Alencar e com o nome da tradutora antes, separado por vírgula, dando a entender que ela seria uma coautora. Já o título varia entre Iracema e Iraçéma, the honey-lips: a legend of Brazil (Figura 8).

Figura 8

Capas de livros de autores brasileiros editados com títulos diferentes

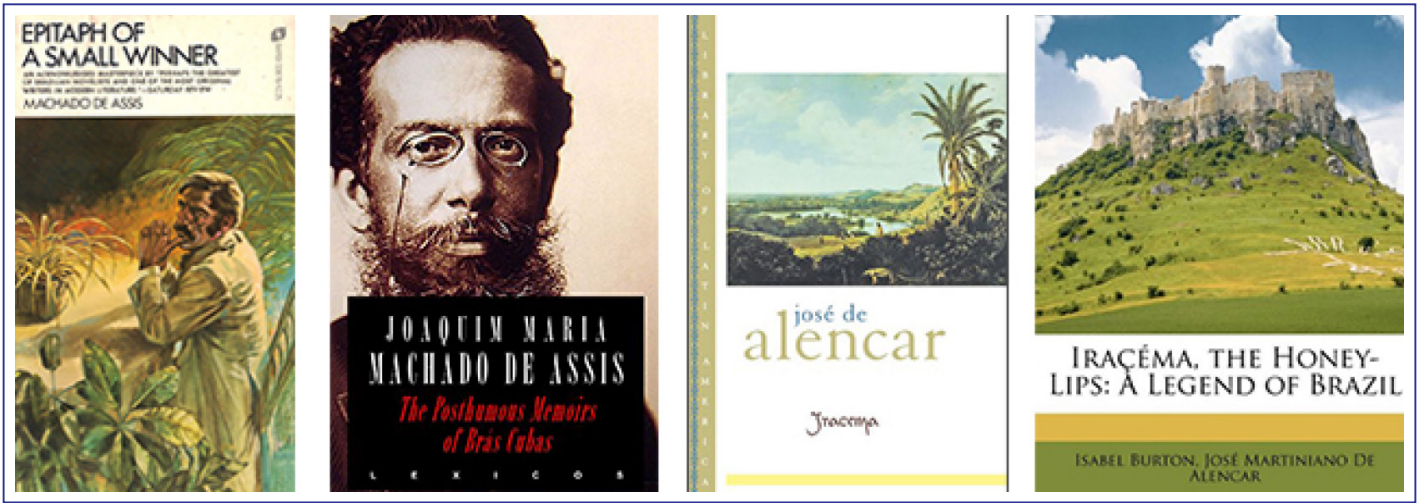

Fonte: Editora Avon Books (1978), Editora Lexicos Books (2018), Editora Oxford University Press (2000) e Editora Nabu Press (2010).

Essa falta de coesão entre as edições não é notada nas capas de romances estadunidenses lançados no Brasil. Nas analisadas de $O$ grande Gastby, por exemplo, autor e título são iguais em todas. Em A cabana do pai Tomás, o título é sempre igual e algumas abreviações ocorrem no nome da autora - por exemplo, H. Beecher Stowe, em vez de Harriet Beecher Stowe, mas nenhum nome é acrescentado. Em $O$ último dos moicanos, nota-se o mesmo tipo de abreviação no nome do autor em algumas capas, enquanto em outras o título aparece no singular: $O$ último moicano. Entretanto, em nenhuma aparecem títulos diferentes para a mesma obra. 
Apesar de Moby Dick ser o título estadunidense com menos capas editadas no Brasil, é aquele que teve mais projetos gráficos especiais desenvolvidos e que apresenta capas na categoria "personagens representados" que melhor interpretam o tema do romance. Na pesquisa de Scheyerl e Siqueira (2008), que analisa a visão dos estrangeiros sobre o Brasil, um dos entrevistados ressaltou que identificava nos brasileiros um desejo forte de imitar a cultura dos Estados Unidos. Sobre a obra do autor, Said (2011) comenta que o capitão Ahab - um dos principais personagens do livro - representa o desejo dos Estados Unidos de conquistar o mundo. Ahab é obcecado pela baleia e se mostra inflexível na busca por ela. Talvez isso justifique, de forma inconsciente, a valorização da obra de Melville no Brasil.

No cenário nacional, nota-se também que nem todas as capas de autores brasileiros editadas no Brasil refletem corretamente o tema da obra. Isso fica claro nas capas de Iracema analisadas na categoria "personagens representados", as quais apresentam diversas influências estrangeiras, tanto na linguagem visual quanto no posicionamento da personagem masculina, que é colocada como homem branco superior. Em outras capas da mesma obra, a figura feminina aparece de lado, de costas, com olhar triste, para baixo, hesitante ou de forma sensualizada (Figura 9).

Figura 9

\section{Capas de Iracema}
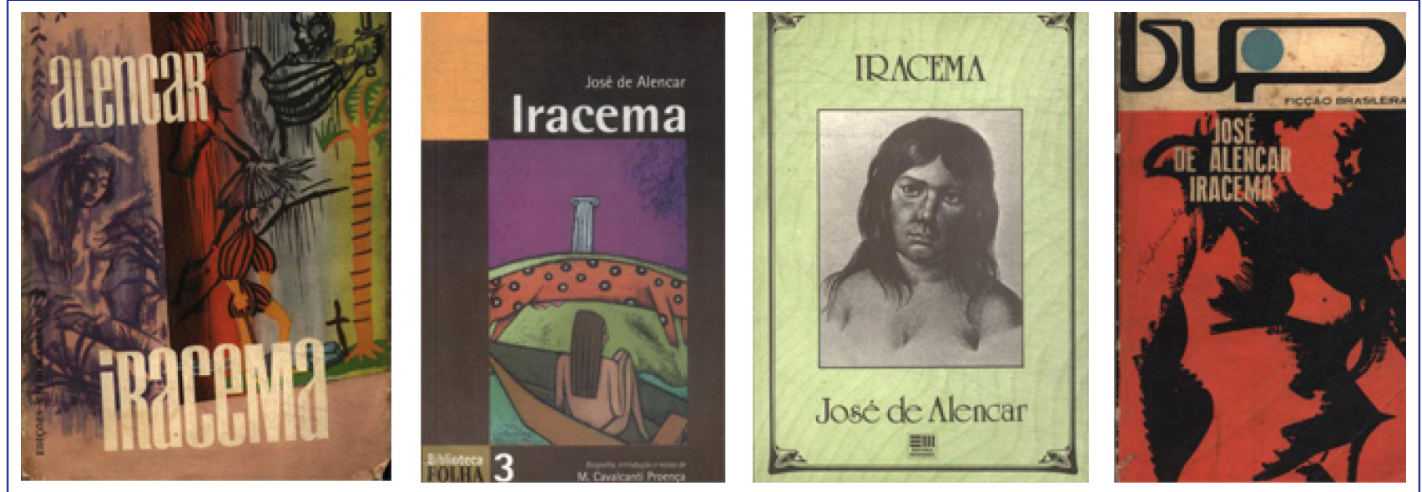

Fonte: Editora Melhoramentos (1967), Editora Ediouro (1997), Editora Moderna (1984) e Editora Biblioteca Universal Popular (1964).

Se nas capas de Iracema, índia brasileira, o homem branco europeu é posicionado de maneira superior a ela dentro da composição visual, nas capas de $O$ último dos moicanos, índio estadunidense, a mulher branca europeia não ganha o mesmo destaque. Pode-se entender que o personagem masculino de origem indígena proveniente do Norte é retratado como mais forte do que a personagem feminina, também de origem indígena, do Sul (Figura 10).

Figura 10

Comparação entre personagens de origem indígena

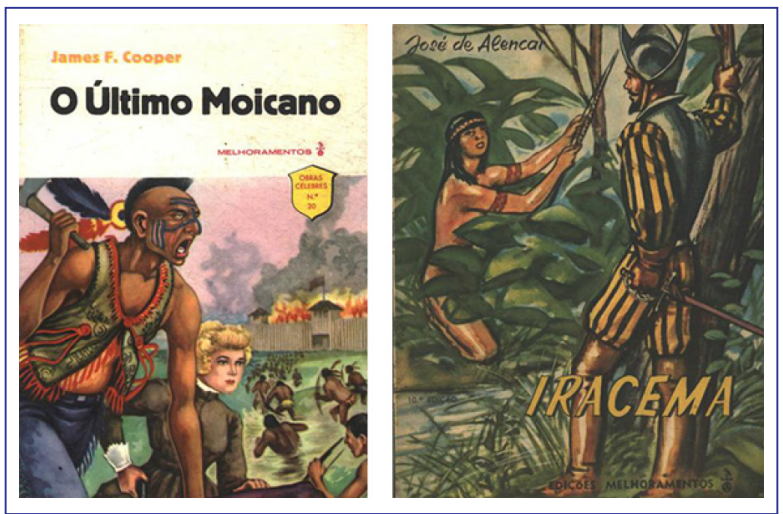

Fonte: Editora Melhoramentos $(1967,1965)$. 
O tema da obra Memórias póstumas de Brás Cubas também não é bem representado nas capas analisadas na categoria "paisagem", nas quais aparecem paisagens do Rio de Janeiro de antigamente. Uma das características dos livros realistas de Machado de Assis é a quase ausência da descrição de paisagens. A ênfase está na elaboração do perfil psicológico das personagens e na reflexão filosófica (Castello, 1953). Portanto, uma capa com paisagem pouco reflete o sentido da obra (Figura 11).

Figura 11

Capas de Memórias póstumas de Brás Cubas com paisagem

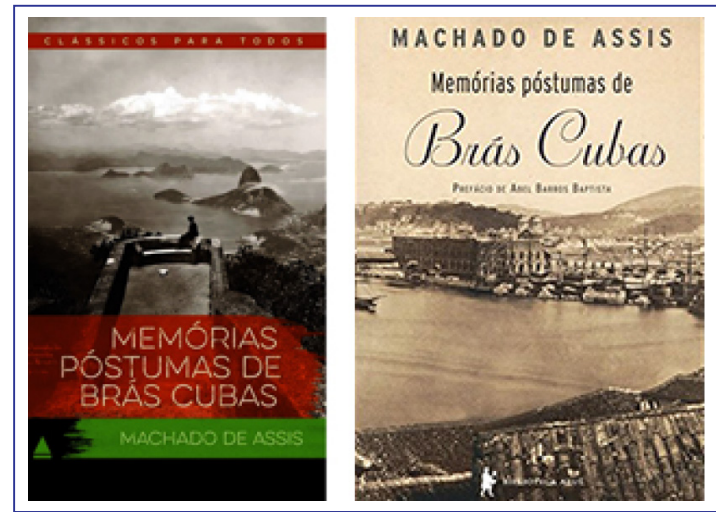

Fonte: Editora Nova fronteira (2016) e Editora Biblioteca Azul (2007).

Quando são representados as personagens desse livro, também não há coerência com o tema da obra em algumas capas. A imagem de um Brás Cubas alegre não condiz com a reflexão pessimista que ele faz da vida durante toda a narrativa. Em outra capa, a mesma pintura de Belmiro de Almeida é usada, por outra editora, para ilustrar a obra Dom Casmurro, que tem um tema diferente de Memórias póstumas (Figura 12).

Figura 12

Capas com um Brás Cubas alegre e com a mesma imagem usada em outro romance

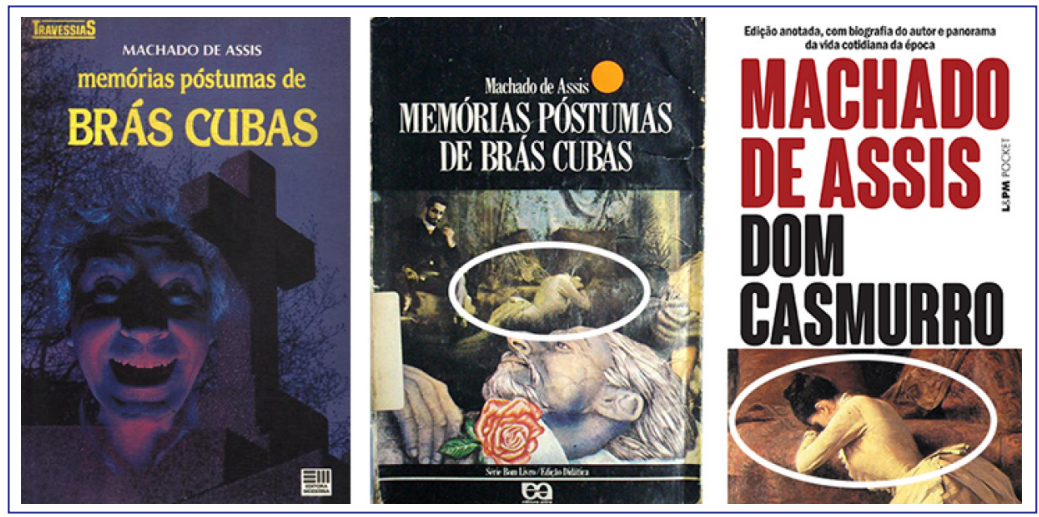

Fonte: Editora Moderna (1988), Editora Ática (1991) e Editora L\&PM (1997).

Uma obra que vai na contramão do que foi descrito acima é Os sertões. Das 28 capas analisadas, 26 mostram, de maneira coerente, o tema do romance, seja por meio de personagens, ícones, paisagens, seja pela imagem do autor.

Ainda existe interesse em editar os clássicos brasileiros do século XIX. Porém, a valorização dos estrangeiros no país é grande, como mostrado antes na Figura 6. A Coleção Clássicos Zahar, do Grupo Companhia das Letras, por exemplo, tem somente 1 título de autor brasileiro de um total de 87 publicações. ${ }^{5} \mathrm{Em}$ 2015, publicaram $O$ ateneu, de Raul Pompeia, e alegaram que esse título inaugurava a publicação de autores brasileiros na coleção, mas nenhum outro foi lançado.

\footnotetext{
${ }^{5}$ Recuperado de zahar.com.br/classicoszahar
} 
Apesar dos pontos negativos destacados, um ponto positivo está no fato de haver uma grande quantidade de capas brasileiras para as obras nacionais, várias delas com qualidade (Figura 13). Isso reflete o interesse das editoras em continuar publicando e dos leitores em continuar consumindo as obras de autores nacionais. O número inferior de capas de Gabriela, cravo e canela, quando comparado à de outros títulos brasileiros, justifica-se pelo fato de esse ser o único livro que ainda não entrou em domínio público.

Figura 13

Capas brasileiras de obras nacionais

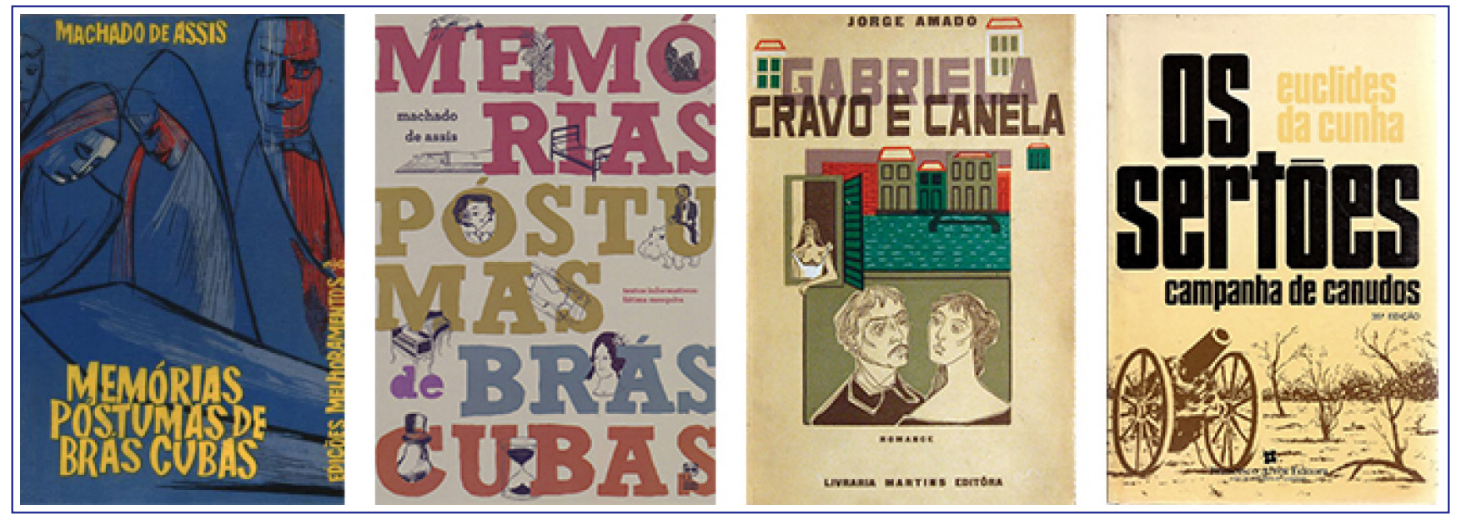

Fonte: Editora Melhoramentos (1967), Editora Panda Books (2018), Editora Martins (1958) e Editora Francisco Alves (1979).

Além disso, editoras brasileiras como Carambaia, Antofágica e Ubu começaram a lançar, a partir de 2016, edições especiais dos clássicos brasileiros, todas em capa dura (Figura 14). Para citar apenas os títulos que constam nesta análise, a Carambaia lançou 3 edições de Memórias póstumas de Brás Cubas. A que é chamada por eles de "especial" tem capa em tecido, gravuras exclusivas impressas manualmente e tiragem de apenas 100 exemplares numerados. A Antofágica lançou a mesma obra, com as ilustrações originais de Candido Portinari, notas inéditas e textos extras de especialistas na obra de Machado de Assis. A Ubu lançou 2 versões de Os sertões, ambas críticas, organizadas por Walnice Nogueira Galvão, especialista em Euclides da Cunha, e que contemplam uma fortuna crítica, a reprodução de páginas das cadernetas de campo do autor e imagens do único registro fotográfico conhecido do conflito. A que é chamada pela editora de "edição completa" é apresentada em um boxe com dois volumes, o segundo dedicado à análise comparativa das diferentes versões publicadas de Os sertões enquanto Euclides da Cunha estava vivo.

Figura 14

Edições especiais de livros brasileiros publicados por editoras nacionais

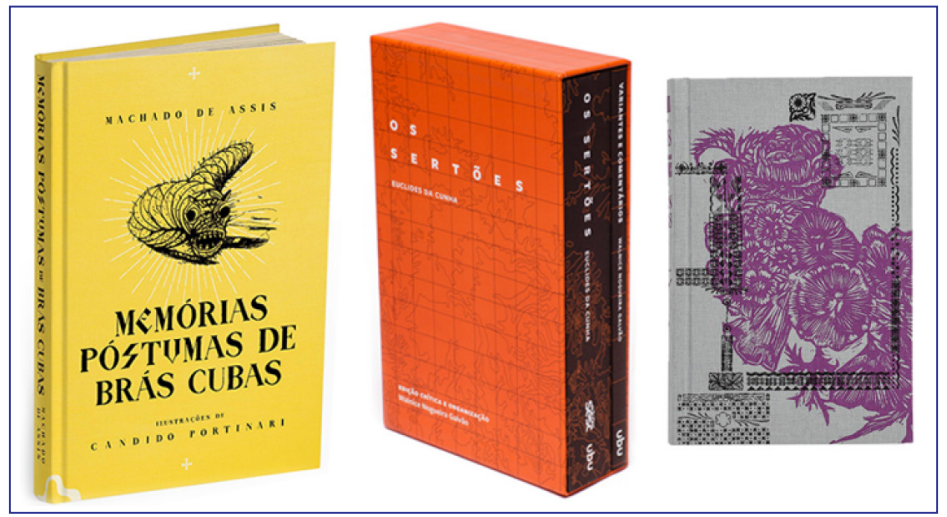

Fonte: Editora Antofágica (2019), Ubu Editora (2019) e Editora Carambaia (2018). 


\section{DISCUSSÃO PÓS-COLONIAL SOBRE AS CAPAS DE LIVROS CLÁSSICOS ESTADUNIDENSES E BRASILEIROS}

Said explica que o mundo eurocêntrico se impôs globalmente como o centro não somente por sua força política e militar, mas também porque sua cultura é tida - pelos próprios eurocêntricos - como superior, portanto mais merecedora de expansão, a fim de "guiar e/ou instruir o indivíduo não europeu ou periférico" (Said, 2011). Nesse processo, tais povos passaram a internacionalizar sua visão sobre o resto do mundo e a ditar como o Sul deveria ser considerado por todos, inclusive pelas sociedades do próprio Sul. Assim, naturalmente, a imagem do que vem a ser esse espaço epistêmico passa pelos filtros de autores do Norte, que interpretam o Sul de maneira parcial, representando-o de modo torpe, pois suas ontologias e epistemologias não o qualificam para enxergá-lo diferentemente, como um lócus de igual importância ao seu (Said, 2007).

Com a teorização de Said sobre orientalismo, é possível perceber que a cultura brasileira não é representada nas capas lançadas nos Estados Unidos com a mesma adequação que a cultura estadunidense é retratada nas capas editadas no Brasil. Os elementos visuais adotados nas capas originais das obras estadunidenses são mantidos nas editadas no Brasil, o que não se pode dizer das capas de títulos brasileiros editados naquele país. O que ocorre, pois, é uma tentativa de representar, com o olhar estrangeiro (Said, 2007), por meio de ícones ou paisagens, os temas brasileiros retratados nas obras. O resultado é que não se vê nas capas estadunidenses o reflexo do material produzido no Brasil, como se não fosse necessário ou admissível usar como referência a linguagem gráfica criada num país considerado por eles inferior (Scheyerl \& Siqueira, 2008).

Assim, percebe-se uma inadequação na forma como personagens, cultura, paisagens, imagens, cores, nomes de autores e títulos de livros são representados por editoras estadunidenses nas capas de clássicos brasileiros. Em geral, tais representações remetem a certa inferioridade da sociedade brasileira em comparação com as do Norte, sendo necessário, inclusive, explicar ao leitor que tais livros são obras "brasileiras ou latino-americanas" - ou seja, separadas do mundo eurocêntrico -, em vez de universais, como as estadunidenses são proclamadas. As capas de livros aqui analisadas, portanto, reforçam a hierarquização de importância geopolítica entre o Norte e o Sul, cujas bases de comparação são criadas e dominadas pelo mundo eurocêntrico (Said, 2007).

A área de marketing é, em geral, alheia a tais discussões pós-coloniais (Jack, 2008; Varman, 2018), em especial no que se refere à geopolítica por trás de capas de clássicos estadunidenses e brasileiros. Naturaliza-se que os elementos do composto de marketing, como o $\mathrm{P}$ de produto aqui analisado - neste estudo representado pelo livro e por seu projeto gráfico -, são sempre tratados de forma não geopolítica pela literatura da área. Todavia, mesmo nesse nível de micromarketing, é possível perceber traços do orientalismo do Norte ainda presentes, tanto no estudo atual quanto em outros originários do Sul (Touzani et al., 2016; Varman \& Costa, 2013). Em comum a esses estudos está a noção de que, por meio de diferentes artifícios de marketing, entre eles produtos e propagandas, é criado um discurso pelo Norte que caracteriza o Sul como distante da realidade eurocêntrica.

Refletir, com base em perspectivas pós-coloniais, sobre o que são produtos ou comunicações de marketing, em especial quando estes são associados a empresas ou organizações vindas de espaços epistemológicos diferentes, é importante para expandir esses conceitos e tornar seu entendimento menos alheio às questões geopolíticas aqui apresentadas. Dessa forma, será possível tratar tais artifícios de marketing de forma menos ingênua, deixando claro para consumidores, sobretudo os do Sul, o cenário mais amplo sobre o que verdadeiramente está por trás de simbolismos e significados daquilo que consomem. Talvez, assim, possamos imaginar um marketing mais em linha com os princípios de valorização - e até de soberania - do consumidor não só no Norte, porém, mais ainda, no Sul. 


\section{CONSIDERAÇÕES FINAIS}

O presente estudo buscou analisar como são representados o Norte e o Sul no projeto gráfico de capas de livros clássicos brasileiros e estadunidenses editados nos dois países. Para isso, foi realizada uma análise semiótica de 304 capas com as características descritas, tendo como base a teorização de orientalismo desenvolvida por Said (2007). Pela análise aqui apresentada, verificaram-se elementos geopolíticos no projeto gráfico das capas dos livros, visto que símbolos estadunidenses são reforçados nas capas editadas no Brasil, as quais repetem as representações das editoras de seu país original, enquanto o mesmo não pode ser dito sobre os símbolos brasileiros representados nas capas editadas nos Estados Unidos. Nesse segundo caso, os estímulos gráficos são usados para criar uma representação sobre o Brasil, em particular, e o Sul, em geral, que retrata a visão que o Norte, liderado pelos Estados Unidos, tem e quer fixar sobre sociedades não eurocêntricas.

É compreensível que essas discussões e preocupações sobre a geopolítica em marketing sejam pouco refletidas pela área, dado que a disciplina é historicamente dominada pelo Norte (Jack, 2008; Varman, 2018). É bem possível, assim, que pesquisadores da área que seguem tal epistemologia dominante não tenham consciência do fenômeno aqui analisado ou de outros relacionados a questões pós-coloniais, pois não são eles que vivenciam o controle experimentado pelo Sul. Cabe a pesquisadores imbuídos dessa episteme "outra" trazer à tona os problemas causados por tamanha imposição exógena, que restringe sua forma de pensar, agir e ser (Said, 2007).

Fundamental para isso seria olhar o marketing praticado e pensado no Sul baseado na epistemologia do Sul. Possivelmente, dessa forma, outras facetas começariam a ser evidenciadas, ajudando a área a identificar o que de fato é benéfico para consumidores, tanto do mundo eurocêntrico quanto do não eurocêntrico. É possível imaginar que esse olhar sobre marketing facilitaria a maior aceitação de discussões geopolíticas dentro da área, a fim de que, aos poucos, análises pós-coloniais em marketing, como a realizada aqui, passem a ser mais comuns.

Foi possível perceber, na presente pesquisa, que algumas editoras brasileiras utilizam composições visuais que não valorizam a cultura nacional ou reforçam negativamente a imagem dos personagens brasileiros. Assim, acredita-se ser importante que as editoras brasileiras deem mais atenção à criação das capas dos clássicos brasileiros para não reforçar visões distorcidas sobre a cultura nacional, que podem refletir a ideia que o Norte fez daqueles que compõem o Sul sem essa visão ser realmente verdadeira.

De acordo com Quijano (2007, p. 177), é preciso livrar os latino-americanos do poder colonial. Para isso, é necessária uma comunicação intercultural em que haja "um intercâmbio de experiências e significados", possibilitando o surgimento de uma racionalidade que pode "legitimamente pretender alguma universalidade". Assim, seria relevante a troca de informações entre editoras brasileiras e estadunidenses, com as quais se mantêm relações comerciais, de modo a incentivar a representação adequada da cultura brasileira nas capas de livros editados nos Estados Unidos, mesmo que esse intercâmbio diga respeito a livros que estão em domínio público.

Estudos futuros podem estender a análise para todo o projeto gráfico do livro - isto é, além da análise da capa, analisar também o miolo. Do mesmo modo, seria relevante ter o livro em mãos, pois isso modifica a percepção de quem o analisa, já que, entre outras coisas, mais fatores seriam levados em consideração, como textura do papel, tamanho do livro e qualidade dos insumos utilizados na impressão.

Além disso, como foi percebido no estudo, seria importante investigar as possíveis causas para o recente interesse das editoras brasileiras em publicar clássicos nacionais em edições especiais, com tratamento diferenciado não só na capa e no miolo, mas também em todo o processo de produção gráfica, que envolve a pesquisa para uso de acabamentos mais sofisticados, como vernizes especiais e hot stamping, além do tipo de impressão mais adequado para ser aplicado em cada parte do livro. Para chegar a essa resposta, é relevante entrevistar o consumidor desse tipo de produto, que se mostra disposto a pagar um preço mais elevado para adquiri-lo e identifica valor numa publicação bem cuidada, apesar de saber que poderia adquirir uma cópia do texto de forma gratuita, já que os livros estão em domínio público. 


\section{REFERÊNCIAS}

Achabe, C. (1988). Hopes and impediments: selected essays 1965-1987. New York, NY: Doubleday.

Ashcroft, B., Griffithsm, G., \& Tiffin, H. (1989). The empire writes back: theory and practice in post-colonial literatures. London, UK: Routledge.

Ashcroft, B., Griffiths, G., \& Tiffin, H. (2007). Post-colonial studies: the key concepts ( $2 \mathrm{a}$ ed.). London, UK: Routledge.

Barros, D. L. P. (2003). Estudos do discurso. In J. L. Fiorin (Org.), Introdução à linguística II: princípios de análise. São Paulo, SP: Contexto.

Bhabha, H. (1994). The location of culture. London, UK: Routledge.

Boschi, M., Barros, D., \& Sauerbronn, J. F. (2016). A introdução da disciplina de marketing no Brasil: "uma linguagem que nos une". Farol-Revista de Estudos Organizacionais e Sociedade, 3(8), 888-956.

Bosi, A. (2004). História concisa da literatura brasileira (36a ed.). São Paulo, SP: Cultrix.

Camargo, L. G. B. (2016). Capas de Santa Rosa. São Paulo, SP: Ateliê Editorial.

Carlson, M. (2008). Intercultural theory postcolonial theory and semiotics. Semiotica - Journal of the International Association for Semiotic Studies, 168, 129-142.

Castello, J. A. (1953). Aspectos do realismo-naturalismo no Brasil. Revista de História, 6(14), 437-456.

Castello, J. A. (2002). The social sciences, epistemic violence, and the problem of the "invention of the other". Views from South, $3(2), 269-285$.

Floch, J. M. (2001). Alguns conceitos fundamentais em semiótica geral (Documentos de estudo do Centro de Pesquisas Sociossemióticas). São Paulo, SP: Edições CPS.

Greimas, A. J., \& Courtés, J. (2008). Dicionário de semiótica. São Paulo, SP: Contexto.

Hallewell, L. (2005). O livro no Brasil: sua história (2a ed.). São Paulo, SP: Edusp.

Hanes, V. L. L. (2014). As traduções de Agatha Christie no Brasil: considerações sobre a representação da oralidade e o pós-colonialismo. Mutatis Mutandis - Revista Latinoamericana de Traducción, 7(2), 306-333.

Heller, S. (2011). O panorama visto do Norte. In C. H. Melo, \& E. Ramos (Orgs.), Linha do tempo do design gráfico no Brasil (Prefácio, pp. 6-9). São Paulo, SP: Cosac Naify.

Hemais, M. W., Pessôa, L. A. G. P, \& Barros, D. F. (2019). The esperanto of business... or how to be successful in life: a postcolonial reading, using semiotics, of advertisements for English courses in Brazil. In Proceedings of 44 Macromarketing Conference, Cleveland, Ohio.

Hölck, L., \& Saiz, M. C. (2010). Educating barbaros: educational policies on the Latin American frontiers between colonies and independent republics (Araucania, Southern Chile/Sonora, Mexico). Paedagogica Historica, 46(4), 435-448.
Jack, G. (2008). Postcolonialism and marketing. In M. Tadajewski, \& D. Brownlie (Orgs.), Critical marketing: issues in contemporary marketing. New Jersey, NJ: Wiley.

Lawes, R. (2020). Using semiotics in marketing: how to achieve consumer insights for brand growth and profits. London, UK: Koganpage.

Lima, V., \& Pessôa, L. A. (2018). O consumo de tecnologia como estruturante identitário: uma discussão teórico-metodológica fundamentada pela Semiótica francesa. Cadernos EBAPE.BR, 16(4), 679-691.

Machado, U. (2017). A capa do livro brasileiro: 1820-1950. São Paulo, SP: Ateliê Editorial.

McEwan, C. (2018). Postcolonialism, decoloniality and Development (2a ed.) New York, NY: Routledge.

Memmi, A. (1992). The colonizer and the colonized. Boston, MA: Beacon Press.

Melo, C. H. (2014). O design gráfico brasileiro: anos 60 (2a ed.). São Paulo, SP: Cosac Naify.

Melo, C. H., \& Ramos, E. (2011). Linha do tempo do design gráfico no Brasil. São Paulo, SP: Cosac Naify.

Mignolo, W. (2009). Epistemic disobedience, independent thought and decolonial freedom. Theory, Culture \& Society, 26(7-8), 159-181.

Mignolo, W. (2011). The darker side of western modernity: global futures, decolonial options. Durham, North Carolina: Duke University.

Noorda, R. (2019). Borrowing place brands: product branding from SMEs in the publishing industry. Journal of Research in Marketing and Entrepreneurship, 21(2), 57-75.

Nurcahya, H. R., Hafiar, H., \& Nugraha, A. R. (2018). Representation of Orientalism in sunsilk print advertising. Journal The Messenger, 10(2), 150-161.

Ozuem, W., Howell, K., \& Lancaster, G. (2019). The impact of digital books on marketing communications. Journal of Retailing and Customer Service, 50, 131-137.

Pessôa, L. A. G. P. (2013). Narrativas de segurança no discurso publicitário: um estudo semiótico. São Paulo, SP: Mackenzie.

Pessôa, L. A. G., Barros, D. F., \& Costa, A. S. M. (2017). Representações da relação homem-carro: uma análise semiótica da propaganda brasileira de seguros de automóvel. Organizações \& Sociedade, 24(80), 15-38.

Quijano, A. (2007). Coloniality and modernity/rationality. Cultural Studies, 21(2-3), 168-178.

Rodrigues, L., \& Hemais, M. (2020). Influências eurocêntricas no Sistema Brasileiro de Autorregulamentação Publicitária: pesquisa histórica sob uma perspectiva decolonial. Cadernos EBAPE.BR, 18(esp.), 794-806.

Said, E. W. (1985). Orientalism reconsidered. Cultural Critique, 1, 89-107.

Said, E. W. (2007). Orientalismo: o Oriente como invenção do Ocidente. São Paulo, SP: Companhia das Letras. 
Said, E. W. (2011). Cultura e imperialismo. São Paulo, SP: Companhia das Letras.

Santos, B. S. (2019). O fim do império cognitivo: a afirmação das epistemologias do Sul (2a reimpr.). Belo Horizonte, MG: Autêntica.

Scheyerl, D., \& Siqueira, S. (2008). O Brasil pelo olhar do outro: representações de estrangeiros sobre os brasileiros de hoje. Trabalhos em Linguística Aplicada, 47(2), 375-391.

Simon, S. (1997). Translation, postcolonialism and cultural studies. Meta-Translators' Journal, 42(2), 462-477.

Spivak, G. C. (2010). Pode o subalterno falar? Belo Horizonte, MG: Editora UFMG.

Teixeira, L. (2008). Leitura de textos visuais: princípios metodológicos. In N. B. Bastos (Ed.), Língua portuguesa - Lusofonia: memória e diversidade cultural. São Paulo, SP: Educ - Editora da PUC-SP.

Touzani, M., Hirschman, E. C., \& Smaoui, F. (2016). Marketing communications, acculturation in situ, and the legacy of colonialism in revolutionary times. Journal of Macromarketing, 36(2), 215-228.

Ünsür, D. (2020). Lost in translation: the misinterpretation of Turkish book covers. Atatürk Üniversitesi Güzel Sanatlar Enstitüsü Dergisi, 26(45), 594-607.
Vanspanckeren, K. (2006). Perfil da literatura americana: edição revisada. Washington, DC: Departamento de Estado dos Estados Unidos da América.

Varman, R. (2018). Postcolonialism, subalternity and critical marketing. In: M. Tadajewski, M. Higgins, J. Denegri-Knott, \& R. Varman (Eds), The Routledge Companion to critical marketing. New York, NY: Routledge.

Varman, R., \& Costa, J. A. (2013). Underdeveloped Other in countryof-origin theory and practices. Consumption, Markets \& Culture, $16(3), 240-265$.

Varman, R., \& Sreekumar, H. (2015). Locating the past in its silence: history and marketing theory in India. Journal of Historical Research in Marketing, 7(2), 272-279.

Veludo-de-Oliveira, T., Quintão, R., \& Urdan, A. (2014). Disciplinas e bibliografia no ensino de marketing nos programas de doutorado em administração no Brasil. Organizações \& Sociedade, 21(71), 661-678.

Young, R. (2003). Postcolonialism: a very short introduction. Oxford, UK: Oxford University Press.

Mariana Luz Eiras Queiroz

ORCID: https://orcid.org/0000-0002-7715-9744

Mestre em Administração de Empresas pela Pontifícia Universidade Católica do Rio de Janeiro (PUC-Rio); Professora Auxiliar do Departamento de Comunicação Social da Pontifícia Universidade Católica do Rio de Janeiro (PUC-Rio). E-mail: marianaeiras@puc-rio.br

Marcus Wilcox Hemais

ORCID: https://orcid.org/0000-0001-9181-8446

Doutor em Administração de Empresas pelo Instituto Coppead de Administração da Universidade Federal do Rio de Janeiro (UFRJ); Professor Adjunto do Departamento de Administração da Pontifícia Universidade Católica do Rio de Janeiro (PUC-Rio). E-mail: marcus.hemais@iag.puc-rio.br

Luís Alexandre Pessôa

ORCID: https://orcid.org/0000-0002-1532-6084

Doutor em Letras pela Universidade Presbiteriana Mackenzie (UPM); Professor Adjunto do Departamento de Administração da Pontifícia Universidade

Católica do Rio de Janeiro (PUC-Rio). E-mail: Ipessoa@iag.puc-rio.br 